\title{
Laparoscopic liver resection for hepatocellular carcinoma in patients with cirrhosis
}

\author{
Jai Young Cho, Ho-Seong Han \\ Department of Surgery, Seoul National University Bundang Hospital, Seoul National University College of Medicine, Seoul 463-707, South Korea.
}

Correspondence to: Dr. Ho-Seong Han, Department of Surgery, Seoul National University Bundang Hospital, Seoul National University College of Medicine, 300 Gumi-dong, Bundang-gu, Seongnam-si, Gyeonggi-do, Seoul 463-707, South Korea. E-mail: hanhs@snubh.org

How to cite this article: Cho JY, Han HS. Laparoscopic liver resection for hepatocellular carcinoma in patients with cirrhosis. Hepatoma Res 2016;2:259-63.

Dr. Ho-Seong Han is a Professor of Department of Surgery, Seoul National University Bundang Hospital, Seoul
National University College of Medicine. He graduated from Seoul National University College of Medicine in
1984 , and finished internship and residency of Department of Surgery at Seoul National University Hospital
in 1989. His field of interest is hepatobiliary surgery and laparoscopic surgery. He performed laparoscopic
right posterior sectionectomy, central bisectionectomy for hepatocellular carcinoma as world-first. He has also
performed laparoscopic liver resection in pediatric patient and succeeded in total laparoscopic right side donor
hepatectomy as world-first. He plays an important role in many societies.

Article history:

Received: 11-05-2016

Accepted: 09-08-2016

Published: 30-09-2016

Key words:

Laparoscopy,

hepatectomy,

cirrhosis,

portal hypertension

\section{INTRODUCTION}

Hepatocellular carcinoma ( $\mathrm{HCC}$ ) is the fifth most common malignant tumor, the most common primary

\begin{abstract}
Hepatocellular carcinoma (HCC) is a common malignant tumor and many cases occur in patients with liver cirrhosis. Although liver transplantation is the most effective treatment option, hepatectomy is still the first curative treatment option because liver transplantation is limited by the donors and high cost. In recent years, laparoscopic liver resection (LLR) has increasingly been performed in patients with liver cirrhosis, and has several advantages over open liver resection. Besides less pain and shorter hospital stay, LLR in patients with liver cirrhosis is also associated with lower incidences of postoperative liver failure and ascites because of greater preservation of collateral veins and less liver manipulation. With increasing experience, LLR for HCC located in segments 7 or 8 is now feasible, and anatomic LLR could be performed in patients with cirrhosis. Many comparative studies have shown that LLR is better than open liver resection in patients with liver cirrhosis in terms of a lower incidence of postoperative liver failure and similar patient survival. In conclusion, LLR is a promising treatment modality for HCC in patients with liver cirrhosis.
\end{abstract}

liver cancer, ${ }^{[1]}$ and the third most common cause of cancer-related death worldwide. ${ }^{[2]}$ Most HCCs are found in patients with liver cirrhosis, although HCC occurs in $60-90 \%$ of all patients with liver cirrhosis. ${ }^{[3]}$

cc) (1) (2) This is an open access article distributed under the terms of the Creative Commons Attribution-

BY NC SA NonCommercial-ShareAlike 3.0 License, which allows others to remix, tweak, and build upon the work non-commercially, as long as the author is credited and the new creations are licensed under the identical terms.

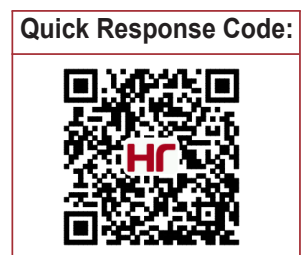

For reprints contact: service@oaepublish.com 
Asian countries, especially, have a disproportionately high prevalence of $\mathrm{HCC}$, mainly because chronic hepatitis $B$ and $C$ viruses are endemic in these countries, ${ }^{[4]}$ and are associated with high risks of liver cirrhosis and HCC. ${ }^{[5]}$

Liver transplantation (LT) appears to be the most attractive treatment option because it treats both the cancer and the underlying disease. However, LT is limited by its high cost and the burden of lifelong immunosuppression. ${ }^{[6,7]}$ Furthermore, the scarcity of donors does not permit LT in all patients with early HCC. ${ }^{[2]}$ With recent technical advances and improvements in postoperative patient management, liver resection for HCC is now considered to be a safer procedure than it was in the past..$^{[8-11]}$ Therefore, liver resection is currently regarded as the first-line treatment in many centers for $\mathrm{HCC}$, especially in patients with compensated cirrhosis. ${ }^{[12]}$

Since the first report of laparoscopic liver wedge resection, steadily increasing numbers of small caseseries have demonstrated the feasibility, adequacy, and safety of laparoscopic liver resection (LLR). ${ }^{[13-16]}$ Now, LLR is commonly performed in patients with $\mathrm{HCC}$ and chronic liver disease.

The aim of this review was to assess the current indications, advantages, and limitations of LLR for HCC in patients with cirrhosis. We also discuss the feasibility of LLR and its oncologic outcomes relative to open surgery.

\section{INDICATIONS}

The indications for LLR have changed substantially since its introduction. In the early stages of LLR, it was limited to benign diseases. With increasing knowledge and experience of this procedure, its indications have expanded to malignant diseases, including HCC and colorectal liver metastasis.[17] However, unlike laparoscopic cholecystectomy, laparoscopy has been limitedly used for liver resection due to the risk of air embolism and the difficulty of parenchymal dissection and bleeding control. ${ }^{[18]}$ Therefore, LLR has been frequently performed for tumors superficially located in the anterolateral segments. ${ }^{[19]}$

For HCC located in segment 7, right posterior sectionectomy is choice of type of resection because it can preserve more functional volume of the liver than right hepatectomy. However, right posterior sectionectomy is technically more difficult and considered as major hepatectomy because it requires parenchymal dissection along the intersectional plane. ${ }^{[20-23]}$ For HCC located in segments 7 or 8 in patients with very poor hepatic reserve, nonanatomical minor liver resection such as tumorectomy is usually performed. However, it is sometimes very difficult and unexpected huge bleeding from hepatic vein could occur because the operative field is poor, intra-abdominal free space is narrow for manipulation of many instruments, and the transection line can be curved or angled. ${ }^{[24]}$ LLR for HCC in the posterosuperior segments in selected patients was reported to be as safe and feasible, and offered comparable oncologic outcomes to open liver resection. Moreover, LLR has other benefits, including reduced blood loss, fewer complications, and shorter postoperative hospital stay than open liver resection. ${ }^{[25]}$

\section{SELECTION OF SUITABLE PATIENTS}

When considering liver resection in patients with cirrhosis, both surgical stress and the oncologic outcomes should be considered. ${ }^{[13]}$ Similar to open surgery, uncompensated cirrhosis is generally considered to be a contraindication for liver resection and hence LLR. ${ }^{[26]}$ Uncontrolled portal hypertension, including esophageal varices and low platelet count, is usually considered as a contraindication for LLR. ${ }^{[27]}$ Because patients with HCC usually have associated chronic liver disease or cirrhosis, these patients may be predisposed to hepatic failure after surgery. Therefore, it is important to preoperatively predict the patient's liver remnant volume and liver function after surgery before selecting the type and extent of liver resection. The hepatic reserve functional capacity is estimated before liver resection to facilitate patient selection and predict the safety margin of parenchymal resection in individual patients.

The Child-Turcotte-Pugh (CTP) score is a simple and the most widely used system for scoringhepatic function before liver resection. It is based on 5 easily measurable variables and, for more than 4 decades, has been considered the gold standard for selecting candidates for liver resection. ${ }^{[28]}$ However, even CTP class A patients may develop liver failure after LLR. ${ }^{[29]}$

The model for end-stage liver disease (MELD) score was made to predict the survival of patients with severe portal hypertension and variceal bleeding who underwent transjugular intrahepatic portosystemic shunt procedure, ${ }^{[30]}$ and then has been further developed for the selection of patients who are waiting for LT. ${ }^{[31]}$ Several studies showed that the application of MELD score to predict mortality in patients who underwent liver resection, not LT worked well, and it may outperform the CTP classification in terms of predicting operative risk before liver resection. ${ }^{[32]}$ However, because MELD score was developed in 
non-surgical setting, it is necessary to validate MELD score in patients undergoing liver resection.

The indocyanine green (ICG) test is one of the most commonly used liver reserved function test in AsiaPacific region. The cut-off value of ICG retention rate at 15 min for safe major liver resection is less than $14 \% .{ }^{[33]}$ However, it is unclear whether this cut-off value is also applicable to patients with liver cirrhosis.

\section{LLR IN PATIENTS WITH CTP CLASS B OR C}

Liver cirrhosis is one of risk factors for developing postoperative morbidities after hepatectomy. ${ }^{[34]}$ Severe blood loss or prolonged ascites after major hepatectomy, especially by open surgery, can occur by interruption of collateral circulation in the parietal wall and surrounding ligamentsin patients with liver cirrhosis. ${ }^{[35]}$ These complications may prolong the postoperative hospital stay or cause hepatic failure in some patients. However, LLR may minimize the reduction in collateral and lymphatic flow caused by laparotomy and mobilization, and may reduce compressive mesenchymal injury, as demonstrated in previous studies of patients undergoing LLR of HCC. ${ }^{[36,37]}$ The benefits of LLR in this setting include earlier ambulation, less postoperative pain, earlier feeding, and a less postoperative complications. Other important advantages of LLR in patients with liver cirrhosis are the lower incidences of postoperative liver failure and ascites due to minimal invasiveness of LLR, which helps to preserve collateral circulation. ${ }^{[13]}$ Therefore, laparoscopic hepatectomy may be a good option in patients with cirrhosis. ${ }^{[38]}$

Most studies consider CTP class B or C cirrhosis to contraindicate liver resection, and surgeons face a considerable challenge in treating patients with uncompensated cirrhosis. There have been a few reports describing the oncological outcomes of patients

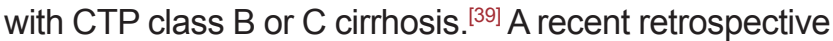
study of 16 patients with CTP class $B$ or $C$ cirrhosis who underwent LLR showed that LLR did not compromise the oncological outcomes of patients with HCC and clinically significant cirrhosis. ${ }^{[40]}$ Recently, precoagulation technique before parenchymal transection, intermittent Pringle maneuver during resection, and hybrid technique using hand port were proposed to decrease the technical difficulty of LLR in cirrhotic liver. ${ }^{[41]}$

\section{ANATOMICAL VERSUS NON-ANATOMICAL RESECTION}

There are still many controversies, but many surgeons believe that anatomical liver resection has some advantages compared to non-anatomical liver resection for $\mathrm{HCC}$ in terms of patient survival and recurrence. ${ }^{[42,43]}$ $\mathrm{HCC}$ recurs after resection mostly in the liver because HCC can spread along the portal branches by microscopic vascular invasion, which contributes to the poor prognosis of $\mathrm{HCC} \cdot{ }^{[44]} \mathrm{On}$ this basis, anatomic resection including the whole segment according to the portal tributaries could remove small microscopic metastasis and prolong patient survival and disease free survival. ${ }^{[45]}$ Anatomical monosegment ectomy of segments 6 or 7 is extremely difficult even in open surgery. ${ }^{[46]}$ For deep seated large tumor in segments 6 or 7, laparoscopic right posterior sectionectomy will be chosen for more resection margin because segmentectomy or tumorectomy could be insufficient. For deep seated tumor near to right hepatic vein, laparoscopic extended right posterior sectionectomy (resection of right posterior section together with right hepatic vein) can be alternative treatment instead of right hemihepatectomy. ${ }^{[4]]}$

\section{ONCOLOGIC OUTCOMES OF LLR IN PATIENTS WITH LIVER CIRRHOSIS AND ITS CHALLENGES}

Several recent studies have compared the oncologic outcomes between LLR and open liver resection. These studies showed that LLR was associated with lower morbidity and mortality rates, but not 5-year overall and disease-free survival rates. ${ }^{[48-50]}$ In addition, the most up-to-date and comprehensive systematic review and meta-analysis prepared at the second international consensus conference on LLR highlighted a reduction in the rates of postoperative ascites and liver failure following LLR in cirrhotic liver. ${ }^{[51,52]}$

Radiofrequency ablation is a compelling alternative to liver resection in patients with liver cirrhosis, especially in terms of the overall morbidities. In patients with peripherally located lesions, percutaneous ablation may carry a high risk of tumor seeding while LLR can be safely performed and may permit pathological assessment of tumor biology and of the surrounding liver parenchyma. ${ }^{[53]}$ One propensity score matching analysis showed that liver resection offered a consistent survival benefit and did not increase the incidence of major complications compared with radiofrequency ablation in patients with hepatitis B virus-related HCC and portal hypertension. ${ }^{[54]}$

\section{CONCLUSION}

LLR has a vital role to play in the first-line treatment of $\mathrm{HCC}$ in selected patients with compensated cirrhosis and portal hypertension. 


\section{Financial support and sponsorship}

None.

\section{Conflicts of interest \\ There are no conflicts of interest.}

\section{Patient consent \\ Not involved.}

\section{Ethics approval Not involved.}

\section{REFERENCES}

1. El-Serag HB, Rudolph KL. Hepatocellular carcinoma: epidemiology and molecular carcinogenesis. Gastroenterology 2007;132:2557-76.

2. Llovet JM, Bruix J. Novel advancements in the management of hepatocellular carcinoma in 2008. J Hepatol 2008;48 Suppl 1:S20-37.

3. Fattovich G, Stroffolini T, Zagni I, Donato F. Hepatocellular carcinoma in cirrhosis: incidence and risk factors. Gastroenterology 2004;127 Suppl 1:S35-50.

4. Kao JH. Risk stratification of HBV infection in Asia-Pacific region. Clin Mol Hepatol 2014;20:223-7.

5. Poon D, Anderson BO, Chen LT, Tanaka K, Lau WY, Van Cutsem E, Singh H, Chow WC, Ooi LL, Chow P, Khin MW, Koo WH; Asian Oncology Summit. Management of hepatocellular carcinoma in Asia: consensus statement from the Asian Oncology Summit 2009. Lancet Oncol 2009;10:1111-8.

6. Bruix J, Sherman M, Llovet JM, Beaugrand M, Lencioni R, Burroughs AK, Christensen E, Pagliaro L, Colombo M, Rodés J; EASL Panel of Experts on HCC. Clinical management of hepatocellular carcinoma. Conclusions of the Barcelona-2000 EASL conference. European Association for the Study of the Liver. J Hepatol 2001;35:421-30.

7. Bruix J, Reig M, Sherman M. Evidence-based diagnosis, staging, and treatment of patients with hepatocellular carcinoma. Gastroenterology 2016;150:835-53.

8. Fan ST, Lo CM, Liu CL, Lam CM, Yuen WK, Yeung C, Wong J. Hepatectomy for hepatocellular carcinoma: toward zero hospital deaths. Ann Surg 1999;229:322-30.

9. Jaskille A, Schechner A, Park K, Williams M, Wang D, Sava J. Abdominal insufflation decreases blood loss and mortality after porcine liver injury. $J$ Trauma 2005;59:1305-8.

10. Poon RT, Fan ST, Lo CM, Ng IO, Liu CL, Lam CM, Wong J. Improving survival results after resection of hepatocellular carcinoma: a prospective study of 377 patients over 10 years. Ann Surg 2001;234:63-70.

11. Belghiti J, Regimbeau JM, Durand F, Kianmanesh AR, Dondero F, Terris B, Sauvanet A, Farges O, Degos F. Resection of hepatocellular carcinoma: a European experience on 328 cases. Hepatogastroenterology 2002;49:41-6.

12. Gaillard M, Tranchart H, Dagher I. Laparoscopic liver resections for hepatocellular carcinoma: current role and limitations. World $J$ Gastroenterol 2014;20:4892-9.

13. Shehta A, Han HS, Yoon YS, Cho JY, Choi Y. Laparoscopic liver resection for hepatocellular carcinoma in cirrhotic patients: 10-year single-center experience. Surg Endosc 2016;30:638-48.

14. Han HS, Yoon YS, Cho JY, Hwang DW. Laparoscopic liver resection for hepatocellular carcinoma: korean experiences. Liver Cancer 2013;2:25-30.

15. Tzanis D, Shivathirthan N, Laurent A, Abu Hilal M, Soubrane O, Kazaryan AM, Ettore GM, Van Dam RM, Lainas P, Tranchart H, Edwin B, Belli G, Campos RR, Pearce N, Gayet B, Dagher I. European experience of laparoscopic major hepatectomy. $J$ Hepatobiliary Pancreat Sci
2013;20:120-4.

16. Ettorre GM, Levi Sandri GB, Santoro R, Vennarecci G, Lepiane P, Colasanti M, Felli E, de Werra E, Colace L, D’Offizi G, Montalbano M, Visco U, Maritti M, Antonini M, Santoro E. Laparoscopic liver resection for hepatocellular carcinoma in cirrhotic patients: single center experience of 90 cases. Hepatobiliary Surg Nutr 2015;4:320-4.

17. KoffronA, Geller D, Gamblin TC,Abecassis M. Laparoscopic liver surgery: shifting the management of liver tumors. Hepatology 2006;44:1694-700.

18. Buell JF, Thomas MJ, Doty TC, Gersin KS, Merchen TD, Gupta M, Rudich SM, Woodle ES. An initial experience and evolution of laparoscopic hepatic resectional surgery. Surgery 2004;136:804-11.

19. Cherqui D, Husson E, Hammoud R, Malassagne B, Stéphan F, Bensaid S, Rotman N, Fagniez PL. Laparoscopic liver resections: a feasibility study in 30 patients. Ann Surg 2000;232:753-62.

20. Muangkaew P, Cho JY, Han HS, Yoon YS, Choi Y, Jang JY, Choi H, Jang JS, Kwon SU. Defining surgical difficulty according to the perceived complexity of liver resection: validation of a complexity classification in patients with hepatocellular carcinoma. Ann Surg Oncol 2016;23:2602-9.

21. Lee MK 4th, Gao F, Strasberg SM. Perceived complexity of various liver resections: results of a survey of experts with development of a complexity score and classification. J Am Coll Surg 2015;220:64-9.

22. Lee MK 4th, Gao F, Strasberg SM. Completion of a liver surgery complexity score and classification based on an international survey of experts. J Am Coll Surg 2016;223:332-42.

23. Cho JY, Han HS, Yoon YS, Shin SH. Feasibility of laparoscopic liver resection for tumors located in the posterosuperior segments of the liver with a special reference to overcoming current limitations on tumor location. Surgery 2008;144:32-8.

24. Dagher I, Proske JM, Carloni A, Richa H, Tranchart H, Franco D Laparoscopic liver resection: results for 70 patients. Surg Endosc 2007;21:619-24.

25. Xiao L, Xiang LJ, Li JW, Chen J, Fan YD, Zheng SG. Laparoscopic versus open liver resection for hepatocellular carcinoma in posterosuperior segments. Surg Endosc 2015;29:2994-3001.

26. Soubrane O, Goumard C, Laurent A, Tranchart H, Truant S, Gayet B Salloum C, Luc G, Dokmak S, Piardi T, Cherqui D, Dagher I, Boleslawsk E, Vibert E, Sa Cunha A, Belghiti J, Pessaux P, Boelle PY, Scatton O. Laparoscopic resection of hepatocellular carcinoma: a French survey in 351 patients. HPB (Oxford) 2014;16:357-65

27. Dagher I, Belli G, Fantini C, Laurent A, Tayar C, Lainas P, Tranchart H, Franco D, Cherqui D. Laparoscopic hepatectomy for hepatocellular carcinoma: a European experience. J Am Coll Surg 2010;211:16-23.

28. Farges O, Malassagne B, Flejou JF, Balzan S, Sauvanet A, Belghiti J. Risk of major liver resection in patients with underlying chronic liver disease: a reappraisal. Ann Surg 1999;229:210-5.

29. Cucchetti A, Ercolani G, Vivarelli M, Cescon M, Ravaioli M, La Barba G, Zanello M, Grazi GL, Pinna AD. Impact of model for end-stage liver disease (MELD) score on prognosis after hepatectomy for hepatocellular carcinoma on cirrhosis. Liver Transpl 2006;12:966-71.

30. Malinchoc M, Kamath PS, Gordon FD, Peine CJ, Rank J, ter Borg PC A model to predict poor survival in patients undergoing transjugular intrahepatic portosystemic shunts. Hepatology 2000;31:864-71.

31. Kamath PS, Wiesner RH, Malinchoc M, Kremers W, Therneau TM, Kosberg CL, D'Amico G, Dickson ER, Kim WR. A model to predict survival in patients with end-stage liver disease. Hepatology 2001;33:464-70.

32. Delis SG, Bakoyiannis A, Dervenis C, Tassopoulos N. Perioperative risk assessment for hepatocellular carcinoma by using the MELD score. $J$ Gastrointest Surg 2009;13:2268-75.

33. Fan ST, Lai EC, Lo CM, Ng IO, Wong J. Hospital mortality of major hepatectomy for hepatocellular carcinoma associated with cirrhosis. Arch Surg 1995;130:198-203.

34. Belli G, Fantini C, D’Agostino A, Cioffi L, Langella S, Russolillo N, Belli 
A. Laparoscopic versus open liver resection for hepatocellular carcinoma in patients with histologically proven cirrhosis: short- and middle-term results. Surg Endosc 2007;21:2004-11.

35. Kanazawa A, Tsukamoto T, Shimizu S, Kodai S, Yamazoe S, Yamamoto $\mathrm{S}$, Kubo S. Impact of laparoscopic liver resection for hepatocellular carcinoma with F4-liver cirrhosis. Surg Endosc 2013;27:2592-7.

36. Nguyen KT, Gamblin TC, Geller DA. World review of laparoscopic liver resection-2,804 patients. Ann Surg 2009;250:831-41.

37. Belli G, Limongelli P, Fantini C, D’Agostino A, Cioffi L, Belli A, Russo G. Laparoscopic and open treatment of hepatocellular carcinoma in patients with cirrhosis. Br J Surg 2009;96:1041-8.

38. Morise Z, Kawabe N, Kawase J, Tomishige H, Nagata H, Ohshima H, Arakawa S, Yoshida R, Isetani M. Pure laparoscopic hepatectomy for hepatocellular carcinoma with chronic liver disease. World J Hepatol 2013;5:487-95

39. Abdel-Atty MY, Farges O, Jagot P, Belghiti J. Laparoscopy extends the indications for liver resection in patients with cirrhosis. $\mathrm{Br} J$ Surg 1999;86:1397-400.

40. Brytska N, Han HS, Shehta A, Yoon YS, Cho JY, Choi Y. Laparoscopic liver resection for hepatitis $\mathrm{B}$ and $\mathrm{C}$ virus-related hepatocellular carcinoma in patients with Child B or C cirrhosis. Hepatobiliary Surg Nutr 2015;4:373-8.

41. Worhunsky DJ, Dua MM, Tran TB, Siu B, Poultsides GA, Norton JA, Visser BC. Laparoscopic hepatectomy in cirrhotics: safe if you adjust technique. Surg Endosc 2016;30:4307-14.

42. Gold JS, Are C, Kornprat P, Jarnagin WR, Gönen M, Fong Y, De Matteo RP, Blumgart LH, D’Angelica M. Increased use of parenchymal-sparing surgery for bilateral liver metastases from colorectal cancer is associated with improved mortality without change in oncologic outcome: trends in treatment over time in 440 patients. Ann Surg 2008;247:109-17.

43. Ishizawa T, Hasegawa K, Aoki T, Takahashi M, Inoue Y, Sano K, Imamura H, Sugawara Y, Kokudo N, Makuuchi M. Neither multiple tumors nor portal hypertension are surgical contraindications for hepatocellular carcinoma. Gastroenterology 2008;134:1908-16.

44. Vauthey JN, Lauwers GY, Esnaola NF, Do KA, Belghiti J, Mirza N, Curley SA, Ellis LM, Regimbeau JM, Rashid A, Cleary KR, Nagorney
DM. Simplified staging for hepatocellular carcinoma. J Clin Oncol 2002;20:1527-36.

45. Yuki K, Hirohashi S, Sakamoto M, Kanai T, Shimosato Y. Growth and spread of hepatocellular carcinoma. A review of 240 consecutive autopsy cases. Cancer 1990;66:2174-9.

46. Ishizawa T, Gumbs AA, Kokudo N, Gayet B. Laparoscopic segmentectomy of the liver: from segment I to VIII. Ann Surg 2012;256:959-64.

47. Cho JY, Han HS, Yoon YS, Choi Y, Lee W. Outcomes of laparoscopic right posterior sectionectomy in patients with hepatocellular carcinoma in the era of laparoscopic surgery. Surgery 2015;158:135-41.

48. Truant S, Bouras AF, Hebbar M, Boleslawski E, Fromont G, Dharancy S, Leteurtre E, Zerbib P, Pruvot FR. Laparoscopic resection vs. open liver resection for peripheral hepatocellular carcinoma in patients with chronic liver disease: a case-matched study. Surg Endosc 2011;25:3668-77.

49. Belli G, Fantini C, Belli A, Limongelli P. Laparoscopic liver resection for hepatocellular carcinoma in cirrhosis: long-term outcomes. Dig Surg 2011;28:134-40.

50. Han HS, Shehta A, Ahn S, Yoon YS, Cho JY, Choi Y. Laparoscopic versus open liver resection for hepatocellular carcinoma: case-matched study with propensity score matching. J Hepatol 2015;63:643-50.

51. Morise Z, Ciria R, Cherqui D, Chen KH, Belli G, Wakabayashi G. Can we expand the indications for laparoscopic liver resection? A systematic review and meta-analysis of laparoscopic liver resection for patients with hepatocellular carcinoma and chronic liver disease. $J$ Hepatobiliary Pancreat Sci 2015;22:342-52.

52. Xiong JJ, Altaf K, Javed MA, Huang W, Mukherjee R, Mai G, Sutton R, Liu XB, Hu WM. Meta-analysis of laparoscopic $v s$. open liver resection for hepatocellular carcinoma. World J Gastroenterol 2012;18:6657-68.

53. Belli A, Cioffi L, Russo G, Belli G. Liver resection for hepatocellular carcinoma in patients with portal hypertension: the role of laparoscopy. Hepatobiliary Surg Nutr 2015;4:417-21.

54. Qiu J, Zheng Y, Shen J, Zeng QA, Zou R, Liao Y, He W, Li Q, Chen G, Li B, Yuan Y. Resection versus ablation in hepatitis B virus-related hepatocellular carcinoma patients with portal hypertension: a propensity score matching study. Surgery 2015;158:1235-43. 